\title{
Analysis of heat stress in an underground coal mine using computational fluid dynamics
}

\author{
Navin Prasad* and Bindhu Lal \\ Civil and Environmental Engineering, Birla Institute of Technology, Mesra 835 215, India
}

Coal mining plays a significant role in the economy of India. The health and safety of miners working in underground mines is a serious concern. One of the risk factors is with regard to the ventilation systems. Computational fluid dynamics is one of the major tools used to study the air-flow distribution. It helps in understanding the blind galleries which may need adequate ventilation. It also helps suppress the spontaneous heating of poorly ventilated workings and in generating heat-stress plots inside the galleries to ensure the safety of mineworkers.

Keywords: Coal mining, computational fluid dynamics, heat stress, underground mines, ventilation systems.

THE share of coal in the energy sector of India is $54.2 \%$ because the excavation of coal is far more economical than other cleaner sources of energy ${ }^{1}$. In India, $8 \%$ of the coal production is from underground mines and remaining from opencast mines ${ }^{2}$. The underground mining is suitable for extraction of deeper coal seams, whereas opencast mining is suitable for shallow coal seams. Considering the safety point of view, a large number of opencast mines are excavated which will lead to the depletion of surface coal sources. Opencast mining has several issues like rehabilitation of people, slope failure, environmental problems like deforestation, air pollution, groundwater depletion, water pollution, etc. Hence in future there is a need to depend on underground mines for more coal production. One of the main requirements of underground mines is to have a planned ventilation system which ensures supply of sufficient fresh air, and proper distribution and removal of dust and contaminated air. It is important to study the flow behaviour of dust and gases inside different zones of underground mines for a planned ventilation system. Computational fluid dynamics (CFD) plays an important role in modelling the flow behaviour of air and gases in underground mining. A study has been made in the application of CFD in goaf gas management and drainage, goaf heating and long wall dust controls for the health and safety of miners ${ }^{3}$. It includes mathematical and numerical solutions which describe the fluid flow using governing equations. A 3D CFD has been developed to study the respirable flow dust behaviour and methane gas accumulation, and validated

\footnotetext{
*For correspondence. (e-mail: navinprasad2@gmail.com)
}

using field data ${ }^{4}$. CFD modelling has been used in several areas of mining, including prediction of airflow methane and dust dispersion in a room and pillar mining face ${ }^{5}, 3 \mathrm{D}$ simulation for the dynamic characteristics of airflow and dust dispersion in a laneway of coal mine ${ }^{6}$, numerical simulation of airflow distribution in mine blind galleries ${ }^{7}$, CFD simulation of underground mine fires ${ }^{8}$ and methane behaviour in underground coal mines ${ }^{9}$.

In this study CFD is used to simulate parameters like temperature, velocity, pressure and density of air inside different zones of the mine. The simulated data after validation with the field data, are used to determine various heat indices responsible for comfort of the miners at various points inside the galleries. The impact of poor ventilation systems plays an adverse role in the health and safety of miners as well as in the production of coal.

\section{Study area}

The underground coal mine selected for the study is the Shankarpur Colliery of Eastern Coalfield Limited, a subsidiary of Coal India Limited. It is spread over 388.0 ha and is located in the eastern part of India (Ukhra, Durgapur, West Bengal) with the coordinates: lat. $23^{\circ} 39^{\prime} 03^{\prime \prime} \mathrm{N}$ to $23^{\circ} 40^{\prime} 24^{\prime \prime} \mathrm{N}$ and long. $87^{\circ} 12^{\prime} 49^{\prime \prime} \mathrm{E}$ to $87^{\circ} 15^{\prime} 10^{\prime \prime} \mathrm{E}$.

In the development phase of mining, currently three faces are open which are at various locations. In Figure 1, the circular marked areas are the current working faces and the arrow shows the path of air introduced using a forced ventilation system having a PV-200 Axial Flow exhaust fan. The seam thickness was $2.47-3.89 \mathrm{~m}$. The depth of cover of the working from the surface was $119.36 \mathrm{~m}$. The Shankarpur Colliery mine, which has been considered for the case study, is being operated using the bord and pillar method producing 1.5 lakh tonnes per annum.

Table 1 shows the average daily employment on the surface and below ground. It is clear that the maximum number of people are working inside the coal mines and hence these require more attention to provide a good

\begin{tabular}{lc}
$\begin{array}{l}\text { Table 1. Average daily employment } \\
\text { on the surface and in underground mines }\end{array}$ \\
\hline Underground & 833 \\
Surface & 148 \\
Total & 981 \\
\hline
\end{tabular}




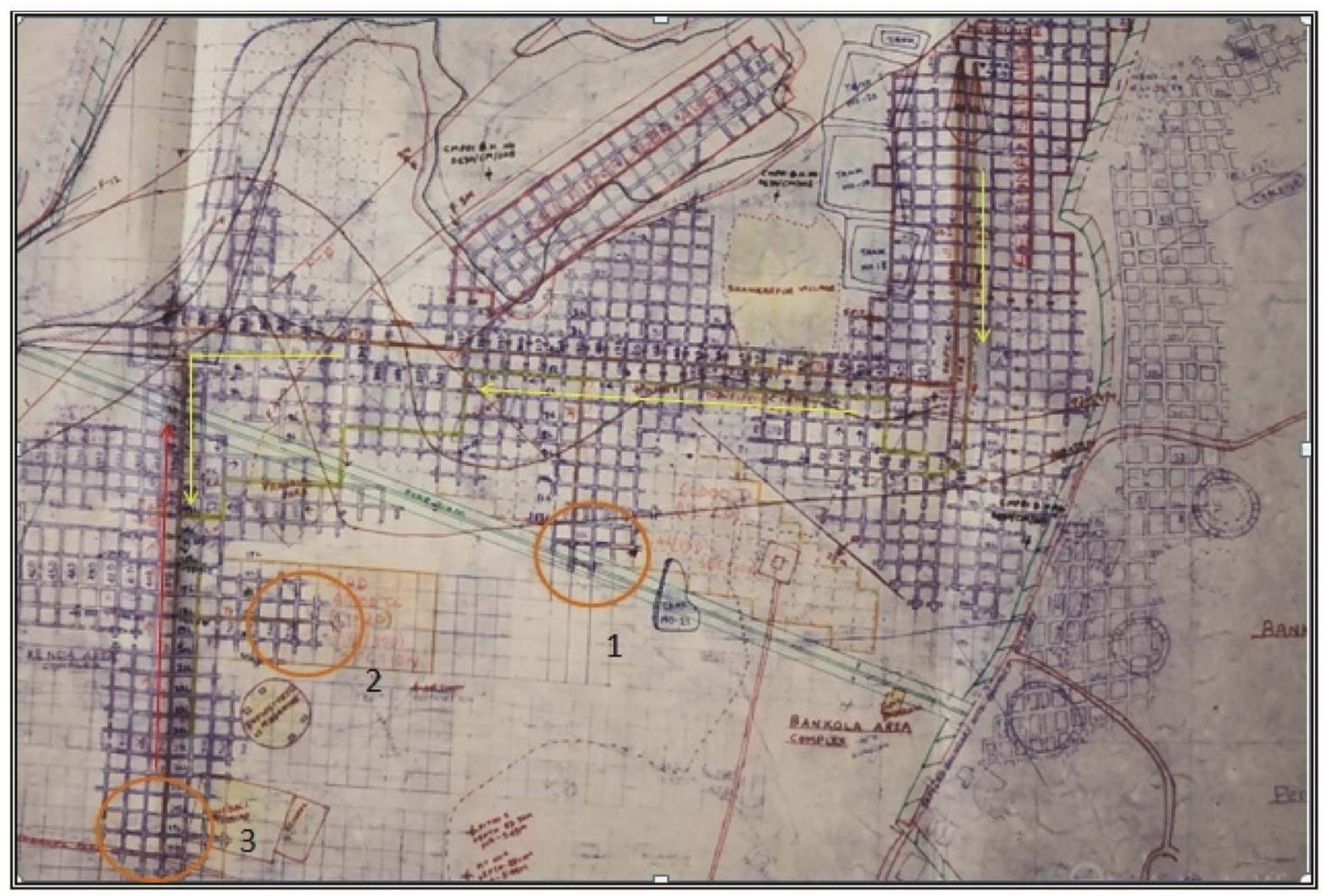

Figure 1. Underground coal mine map of the study area.
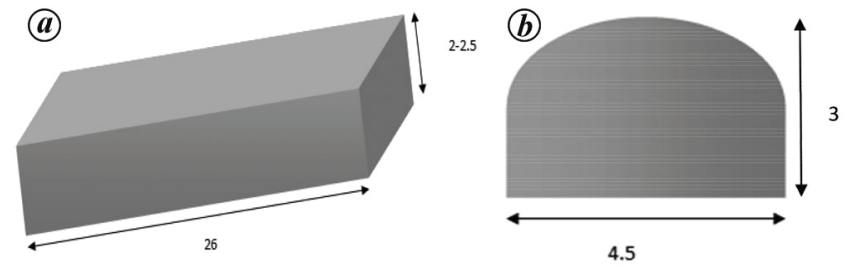

Figure 2. $\boldsymbol{a}$, Dimensions and $3 \mathrm{D}$ models of the pillar. $\boldsymbol{b}$, Dimensions of the working area and front view of the gallery.

working and healthy environment to reduce the number of major and minor accidents.

\section{Geometry, modelling and meshing}

CFD basically uses three stages in solving the fluid problems and analysis. These are pre-processing, solving and post-processing.

In the first stage, geometry is assigned to the CFD model as the shape of pillar and gallery (Figure 2 and Table 2). The driving of galleries in chess board pattern forming rectangular pillars is called development, whereas extraction of these pillars is depillaring. The area from where coal has been extracted is termed as goaf. This is not a working place and no person can enter the area.
Table 2. Dimensions of the pillar and gallery

\begin{tabular}{ll}
\hline Length of the pillar & $26 \mathrm{~m}$ \\
Breadth of the pillar & $26 \mathrm{~m}$ \\
Height of the pillar & $2-2.5 \mathrm{~m}$ \\
Inclination of the coal seam & 1 in $16 \mathrm{~m}$ \\
Depth variation & $90-150 \mathrm{~m}$ \\
Length of the gallery (District 1) & $234 \mathrm{~m}$ \\
Length of the gallery (District 2) & $130 \mathrm{~m}$ \\
Length of the gallery (District 3) & $260 \mathrm{~m}$ \\
Width of the gallery & $4.5 \mathrm{~m}$ \\
Height of the gallery & $3.0 \mathrm{~m}$ \\
\hline
\end{tabular}

Table 3. Distance of three districts from the ventilation system

\begin{tabular}{lcc}
\hline & $\begin{array}{c}\text { Distance from } \\
\text { inlet }(\mathrm{m})\end{array}$ & $\begin{array}{c}\text { Distance from main } \\
\text { ventilation line }(\mathrm{m})\end{array}$ \\
\hline District 1 (face 1) & 806 & 234 \\
District 2 (face 2) & 1456 & 130 \\
District 3 (face 3) & 1820 & 260 \\
\hline
\end{tabular}

Figure 3 and Table 3 show the position of the three working districts of the mine with respect to the ventilation system and their distance from the inlet and outlet. are given return air from one district must not enter into another district according to Regulation 158, Sub-section 1, Coal Mines Regulations, 2017. 


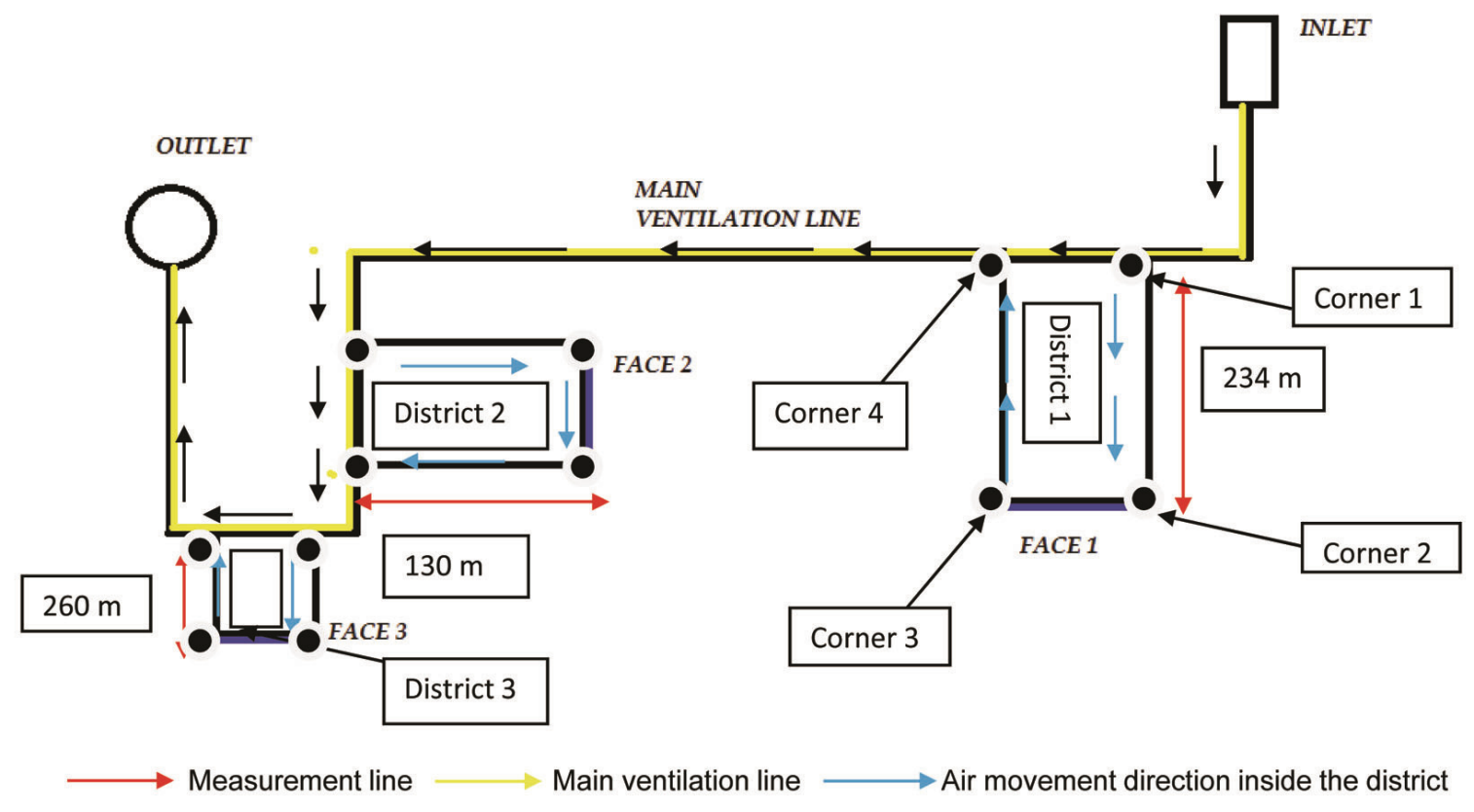

Figure 3. Schematic representation of position of the three districts.

The model is created in ANSYS workbench 14.5 and is meshed with the default meshing tool available. The meshing shape is tetrahedrons with approximately 345,338 elements with 68,608 nodes. The meshing for the projected area (face) has been sized to $0.025 \mathrm{~m}$ and the gallery region near the face area is $0.25 \mathrm{~m}$. CFD geometrical model is developed for the three districts with the same specifications for meshing. The meshing plays an important role in the final solution.

\section{Governing equations}

The governing equations are employed in the second process, which uses the discretization method to deal with each control volume temporally and spatially. There are different types of models available in the ANSYS workbench based on the properties and type of analysis of the given problem. These governing equations for the models are based on the fundamental principle of fluid properties and its physics. In this study, finite grid and nodes are used. The fluid is assumed to be in a steady state with incompressible laminar flow without heat transfer. The governing equations used by the CFD are given below ${ }^{10}$.

Conservation of mass (continuity equation)

$$
\frac{\partial \rho}{\partial t}+\vec{\nabla} \cdot \rho \vec{v}=0
$$

where $\rho$ is the density of the fluid $\left(\mathrm{kg} / \mathrm{m}^{3}\right), t$ the time (s) and $v$ is the velocity vector $(\mathrm{m} / \mathrm{s})$.
Conservation of momentum (Newton's second law)

$$
\frac{\partial(\rho \vec{v})}{\partial t}+\vec{\nabla} \cdot(\rho \vec{v} \vec{v})=\vec{\nabla} \cdot p+\vec{\nabla} \cdot \overline{\bar{\tau}}+\rho \vec{b}
$$

where $\overline{\bar{\tau}}$ is the viscous stress tensor $(\mathrm{N}), \vec{b}$ the body force and $p$ is the fluid pressure $(\mathrm{Pa})$.

Conservation of energy (the first law of thermodynamics)

$$
\begin{aligned}
\frac{\partial \rho e}{\partial t}+\vec{\nabla} \cdot(\rho e \vec{v})=\rho \dot{q}+\vec{\nabla} \cdot(k \vec{\nabla} T)-\vec{\nabla} \cdot(p \vec{v}) \\
+\vec{\nabla} \cdot(\overline{\bar{\tau}} \cdot \vec{v})+\rho \vec{b} \cdot \vec{v}
\end{aligned}
$$

where $e$ represents the internal energy per unit mass, $T$ the temperature, $\dot{q}$ the rate of volumetric heat addition per unit mass and $k$ is the kinetic energy per unit mass.

The stimulated values of temperature, pressure, density and velocity of air are calculated by the model using the above equations and compared with field data. These simulated data are used to calculate heat storage of the body of a miner.

\section{Calculation of heat storage}

The heat storage of the body of a miner in the working environment is given by the sum of individual heat stresses developed by the body through various processes. These can be written as follows

$$
S=M-(C \pm R \pm B \pm E \pm K \pm W)
$$


The internal heat production of the body depends on the metabolic rate $(M)$ and other parameters like mechanical power $(W)$, heat exchange by convection and evaporation in the respiratory tract $(B)$, heat exchange by radiation $(R)$, conduction $(K)$, convection $(C)$ and evaporation $(E)$ on the skin into the atmosphere. All this are expressed in $\mathrm{W} / \mathrm{m}^{2}$.

The heat generation from the body of a worker depends on his metabolic rate, which is in turn depends on the type of work one does in the coal mines (Table 4). According to ISO 7243 (ref. 11), the estimates of metabolic rate for activities are as follows.

Convection heat loss from the body can be calculated as

$$
\begin{aligned}
& C=\frac{T_{\mathrm{sk}}-T_{\mathrm{cl}}}{R_{\mathrm{cl}}}=h_{\mathrm{cl}}\left(T_{\mathrm{sk}}-T_{\mathrm{cl}}\right), \\
& h_{\mathrm{cl}}=8.7 \times V_{\mathrm{a}}^{0.5},
\end{aligned}
$$

where $T_{\mathrm{sk}}$ is the mean skin temperature $\left({ }^{\circ} \mathrm{C}\right), T_{\mathrm{cl}}$ the external temperature of the clothing $\left({ }^{\circ} \mathrm{C}\right), h_{\mathrm{cl}}$ the clothing permeability index $\left(\mathrm{W} /\left(\mathrm{m}^{2} \mathrm{k}\right)\right), R_{\mathrm{cl}}$ the thermal resistance of the clothing which is the reciprocal of the clothing permeability index and $V_{\mathrm{a}}$ is the velocity of air $(\mathrm{m} / \mathrm{s})$. The skin temperature is calculated using the following equation $^{12,13}$

$$
\begin{aligned}
T_{\mathrm{sk}}= & 30+0.138 T_{\mathrm{a}}+\frac{0.245 P_{\mathrm{a}}}{1000}-0.57 V_{\mathrm{a}} \\
& +0.0128 M-0.553 R_{\mathrm{cl}},
\end{aligned}
$$

where $T_{\mathrm{a}}$ is the ambient temperature $\left({ }^{\circ} \mathrm{C}\right), P_{\mathrm{a}}$ the actual vapour pressure $(\mathrm{Pa})$ and $V_{\mathrm{a}}$ is the velocity of air $(\mathrm{m} / \mathrm{s})$. The value of $R_{\mathrm{cl}}$ is taken as 0.093 with its area factor as 1.18 (ref. 14). The overall clothing insulation $\left(I_{\mathrm{cl}}\right)$ can be calculated by the summation of individual clothing insulation values $\left(I_{\text {clu }}\right.$; Table 5$)$ as follows ${ }^{15}$

$$
I_{\mathrm{cl}}\left(\frac{m^{2} K}{W}\right)=0.161+0.835 \sum I_{\mathrm{clu}}
$$

The overall thermal insulation is

$$
I_{\mathrm{cl}}=\frac{0.8983 m^{2} K}{W} .
$$

The clothing temperature $T_{\mathrm{cl}}$ is derived by the algorithm given in the literature ${ }^{16,17}$ by considering the air temperature $T_{\mathrm{a}}\left({ }^{\circ} \mathrm{C}\right)$ as mean radiant temperature $T_{\mathrm{m}}\left({ }^{\circ} \mathrm{C}\right)$ and the value of correlation factor as 1 , where $I_{\mathrm{cl}} \geq 0.6$.

$$
T_{\mathrm{cl}}=\frac{T_{\mathrm{sk}}+0.1774 h_{\mathrm{c}} T_{\mathrm{a}}}{0.1774 h_{\mathrm{c}}+1} .
$$

Radiation heat loss from the body is given as

$$
R=\sigma \varepsilon_{\mathrm{sk}} f_{\mathrm{cl}} F_{\mathrm{vf}}\left[T_{\mathrm{cl}}^{4}-T_{\mathrm{r}}^{4}\right]
$$

where $\sigma$ denotes the Stefan-Boltzmann constant, $f_{\mathrm{cl}}$ the clothing factor which can be calculated using eq. (12) below, $\varepsilon_{\mathrm{sk}}$ the coefficient of skin emissivity which is between 0.95 and 0.97 and $F_{\mathrm{vf}}$ is the view factor between the body and surroundings which is taken as 0.75 .

$$
f_{\mathrm{cl}}=1.05+0.1 I_{\mathrm{cl}}
$$

The mechanical power $(W)$ and conduction losses $(K)$ are very small and can be neglected. The heat exchange through respiration is basically the difference between the inhaled and exhaled air, though the difference is very less and hence can be ignored ${ }^{18}$.

$$
B=1.7 \times 10^{-6} \times M\left(s_{\text {out }}-s_{\text {in }}\right),
$$

where $s_{\text {out }}-s_{\text {in }}$ is the difference of heat exchange between the inhaled and exhaled air $(\mathrm{J} / \mathrm{kg})$. The evaporation heat flow at the skin surface is calculated as follows

$$
E=\frac{P_{\mathrm{sk}}-P_{\mathrm{a}}}{R_{\mathrm{E}}},
$$

where $P_{\text {sk }}$ is the saturation partial vapour pressure at skin temperature and $R_{\mathrm{E}}$ is the evaporative resistivity of the layer separating the cloth and air. Sweat evaporation is a form of latent heat transfer below surfaces. According to ISO 7933 (ref. 19), the maximum amount of dehydration

Table 4. Metabolic rate for the activity of workers inside coal mines

\begin{tabular}{lcc}
\hline Workplace & Range of intervals & Average metabolic rate \\
\hline At rest & $0-117$ & 117 \\
Light work rate & $117-234$ & 175.5 \\
Moderate work rate & $234-360$ & 297 \\
Hard work rate & $360-468$ & 414 \\
Very high work rate & 468 and above & 468 \\
\hline
\end{tabular}

Table 5. Thermal insulation of the tested garments ${ }^{16}$

\begin{tabular}{lc}
\hline Garments & Thermal insulation \\
\hline Underwear pants briefs & 0.04 \\
Trousers straight fitted & 0.22 \\
Socks & 0.02 \\
Shoes & 0.03 \\
Shirts long sleeves shirt collar & 0.31 \\
Working jacket & 0.29
\end{tabular}


RESEARCH ARTICLES

Table 6. Real-time data used as boundary conditions

\begin{tabular}{lcccccc}
\hline District & $\begin{array}{c}\text { Length } \\
(\mathrm{m})\end{array}$ & $\begin{array}{c}\text { Area } \\
\left(\mathrm{m}^{2}\right)\end{array}$ & $\begin{array}{c}\text { Velocity } \\
(\mathrm{m} / \mathrm{min})\end{array}$ & $\begin{array}{c}\text { Mass flow rate } \\
\left(\mathrm{m}^{2} / \mathrm{min}\right)\end{array}$ & $\begin{array}{c}\text { Dry bulb temperature } \\
\left(\mathrm{DBT} ;{ }^{\circ} \mathrm{C}\right)\end{array}$ & $\begin{array}{c}\text { Wet bulb temperature } \\
\left(\text { WBT; }{ }^{\circ} \mathrm{C}\right)\end{array}$ \\
\hline 1 & 234 & 9.2 & 72 & 690 & 28 & 27 \\
2 & 130 & 10.5 & 10 & 105 & 29 & 93 \\
3 & 260 & 11.25 & 20 & 225 & 29 & 93 \\
\hline
\end{tabular}

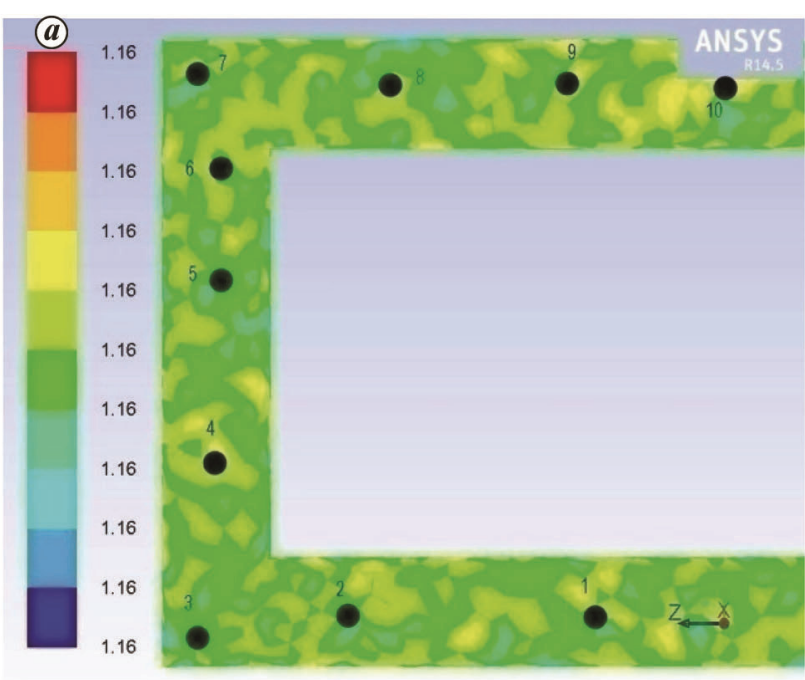

Contours of Density $(\mathrm{kg} / \mathrm{m} 3)$

(b)

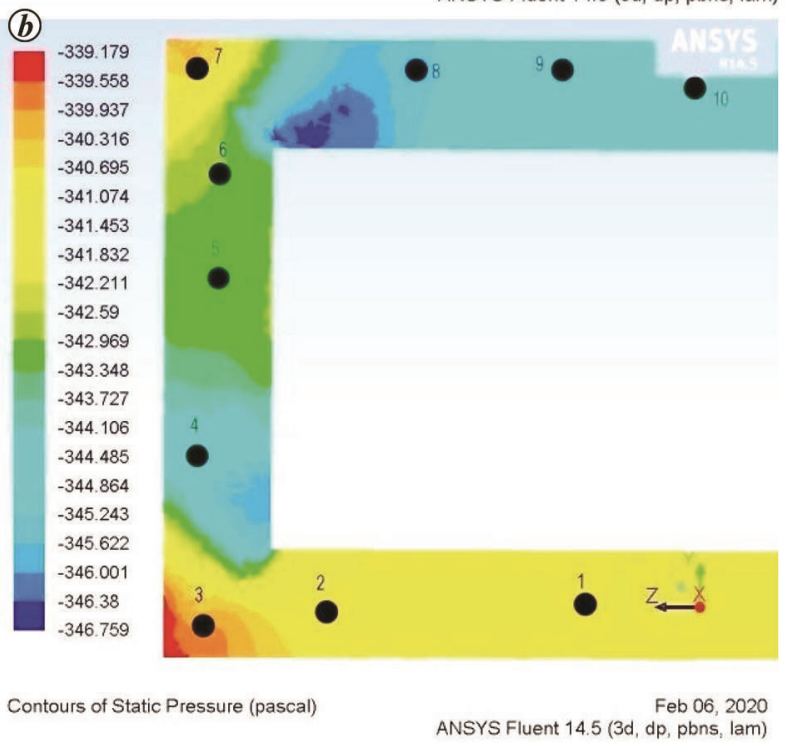

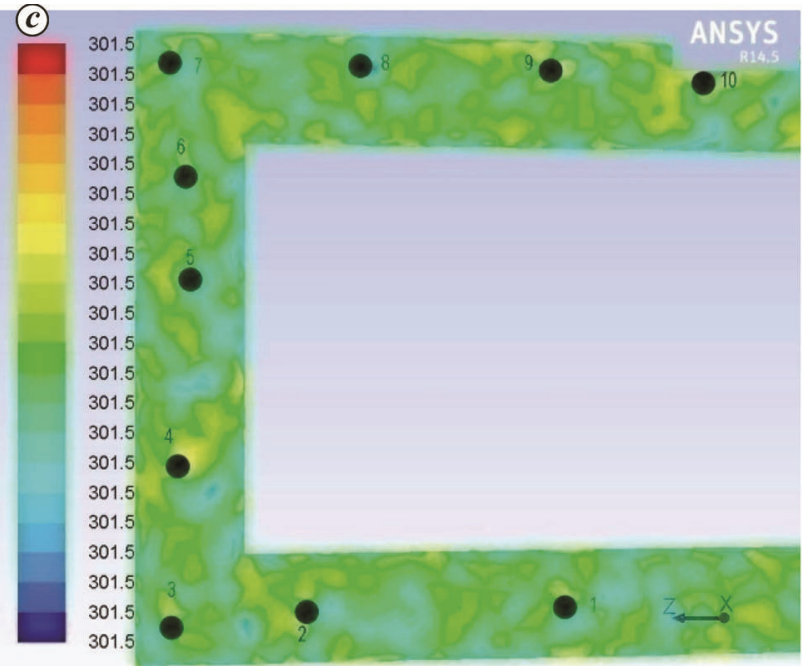

$\begin{array}{rr}\text { Contours of Total Temperature }(k) & \text { Feb 03, } 2020 \\ \text { ANSYS Fluent } 14.5(3 \mathrm{~d} \text {, dp, pbns, lam) }\end{array}$

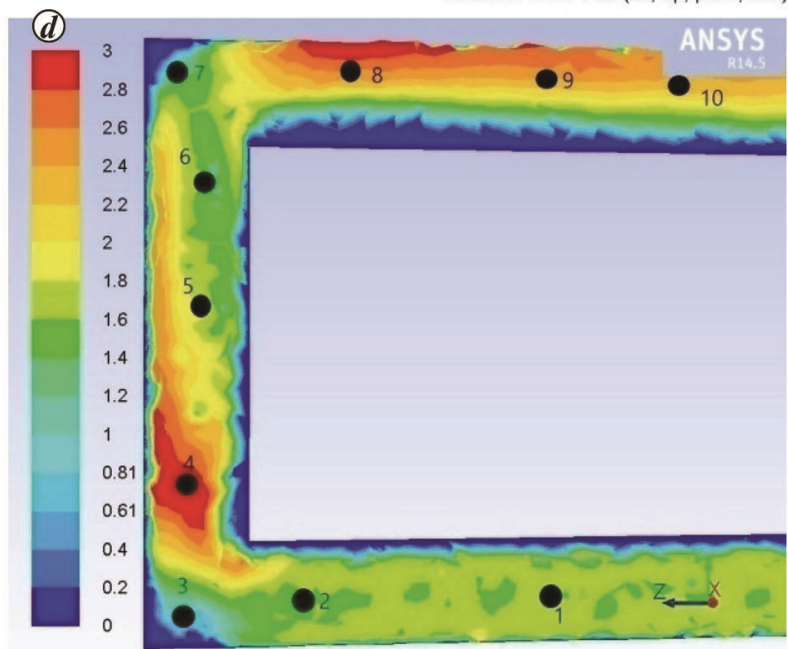

Profiles of Velocity Magnitude $(\mathrm{m} / \mathrm{s})$

Feb 03, 2020
ANSYS Fluent 14.5 (3d, dp, pbns, lam)

Figure 4. Variation of (a) density, $(\boldsymbol{b})$ pressure, $(\boldsymbol{c})$ temperature and $(\boldsymbol{d})$ velocity inside district 1.

allowed for a worker is $3900 \mathrm{~g}$, which is equivalent to sweating heat release of $1.5 \mathrm{kWh} / \mathrm{m}^{2}$ (ref. 20). According to ISO 7933 (ref. 19), this is for 6 to 8 working hours. Therefore $E_{\max }$ here is equal to $187.5 \mathrm{~W} / \mathrm{m}^{2}$ as the upper limit.

\section{Boundary conditions}

Table 6 gives the boundary conditions assigned to the problem. The various parameters inside the galleries like velocity of air, mass flow, dry bulb temperature (DBT) and wet bulb temperature (WBT) are the real-time data from the mines. The velocity is the inlet velocity of air at the entry of each district. According to the mine plan, only development activities are being carried out. The mass flow rate is the amount of air entering inside the gallery with the mentioned DBT and WBT. Relative humidity is constant throughout the area. The moisture content inside the blind galleries is $6.3 \%$. The density of the air is 
RESEARCH ARTICLES

Table 7. Comparison between simulated and measured values for the three districts

\begin{tabular}{|c|c|c|c|c|c|c|c|c|}
\hline & \multicolumn{4}{|c|}{ Simulated } & \multicolumn{4}{|c|}{ Measured } \\
\hline & $\begin{array}{l}\text { Velocity } \\
(\mathrm{m} / \mathrm{min})\end{array}$ & $\begin{array}{c}\text { Temperature } \\
\left({ }^{\circ} \mathrm{C}\right)\end{array}$ & $\begin{array}{c}\text { Pressure } \\
\text { (atm) }\end{array}$ & $\begin{array}{l}\text { Density } \\
\left(\mathrm{kg} / \mathrm{m}^{3}\right)\end{array}$ & $\begin{array}{l}\text { Velocity } \\
(\mathrm{m} / \mathrm{min})\end{array}$ & $\begin{array}{c}\text { Temperature } \\
\left({ }^{\circ} \mathrm{C}\right)\end{array}$ & $\begin{array}{l}\text { Pressure } \\
\text { (atm) }\end{array}$ & $\begin{array}{l}\text { Density } \\
\left(\mathrm{kg} / \mathrm{m}^{3}\right)\end{array}$ \\
\hline \multirow[t]{4}{*}{ District 1} & 72 & 28.5 & 0.99 & 1.16 & 72 & 28 & 1 & 1.164 \\
\hline & 35.5 & 28.5 & 0.99 & 1.16 & 37 & 28 & 1 & 1.164 \\
\hline & 53.22 & 28.5 & 0.99 & 1.16 & 55 & 28 & 1 & 1.164 \\
\hline & 86.4 & 28.5 & 0.99 & 1.16 & 88 & 28 & 1 & 1.164 \\
\hline \multirow[t]{4}{*}{ District 2} & 10 & 29 & 0.99 & 1.16 & 10 & 29 & 1 & 1.164 \\
\hline & 2.682 & 32 & 0.99 & 1.16 & 5 & 30 & 1 & 1.164 \\
\hline & 1.8 & 30.5 & 0.99 & 1.16 & 3 & 30 & 1 & 1.164 \\
\hline & 14.28 & 30.5 & 0.99 & 1.16 & 15 & 30 & 1 & 1.164 \\
\hline \multirow[t]{4}{*}{ District 3} & 20 & 29 & 0.99 & 1.16 & 20 & 29 & 1 & 1.164 \\
\hline & 9 & 29.2 & 0.99 & 1.16 & 11 & 29 & 1 & 1.164 \\
\hline & 13.26 & 29.2 & 0.99 & 1.16 & 15 & 29 & 1 & 1.164 \\
\hline & 21.6 & 29.6 & 0.99 & 1.16 & 23 & 29 & 1 & 1.164 \\
\hline
\end{tabular}

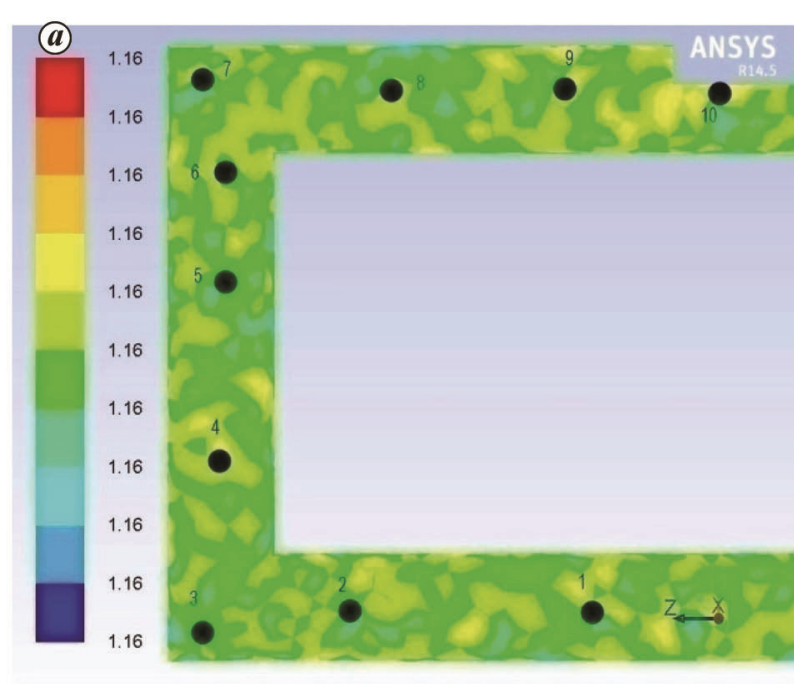

Contours of Density $(\mathrm{kg} / \mathrm{m} 3)$

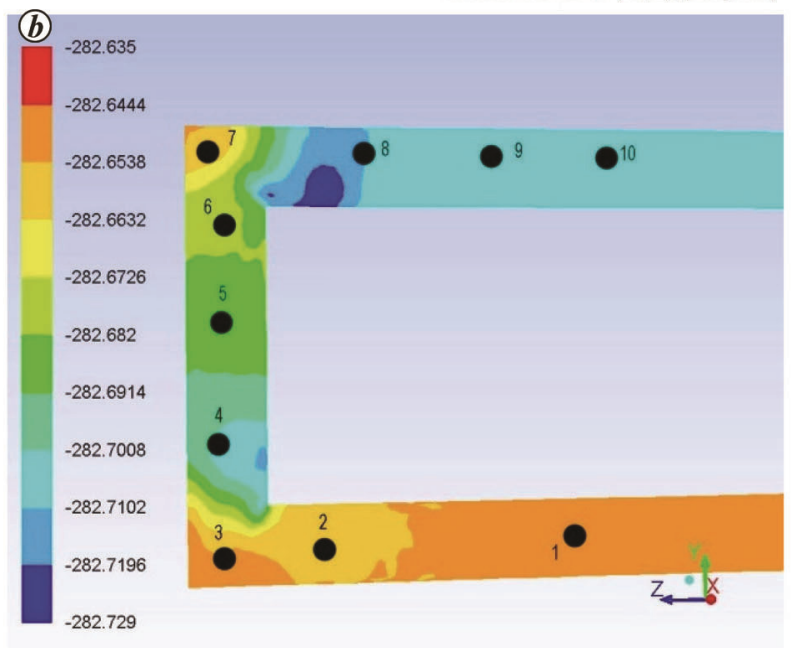

Contours of Static Pressure (pascal)

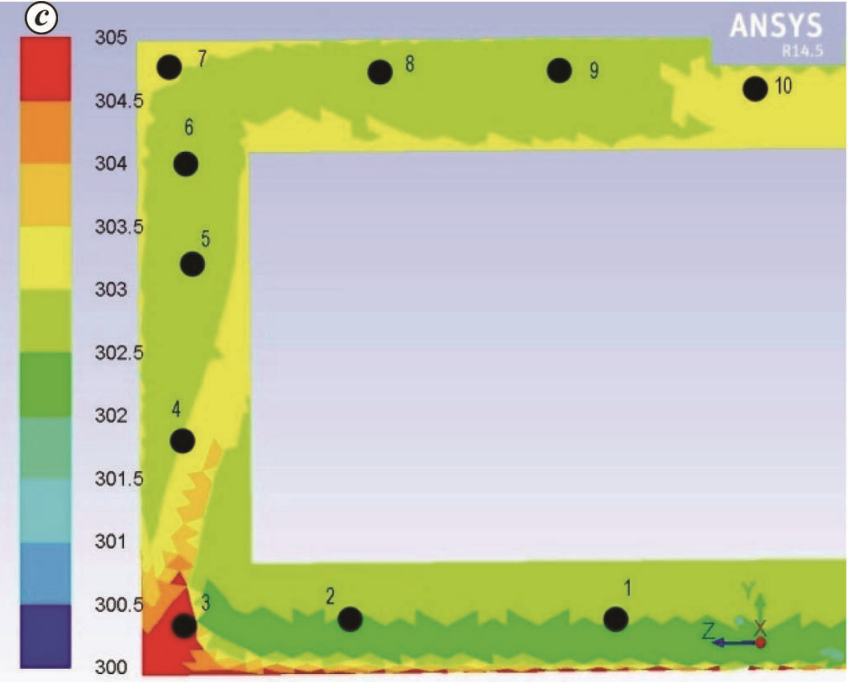

Contours of Static Temperature (k) Feb 07, 2020

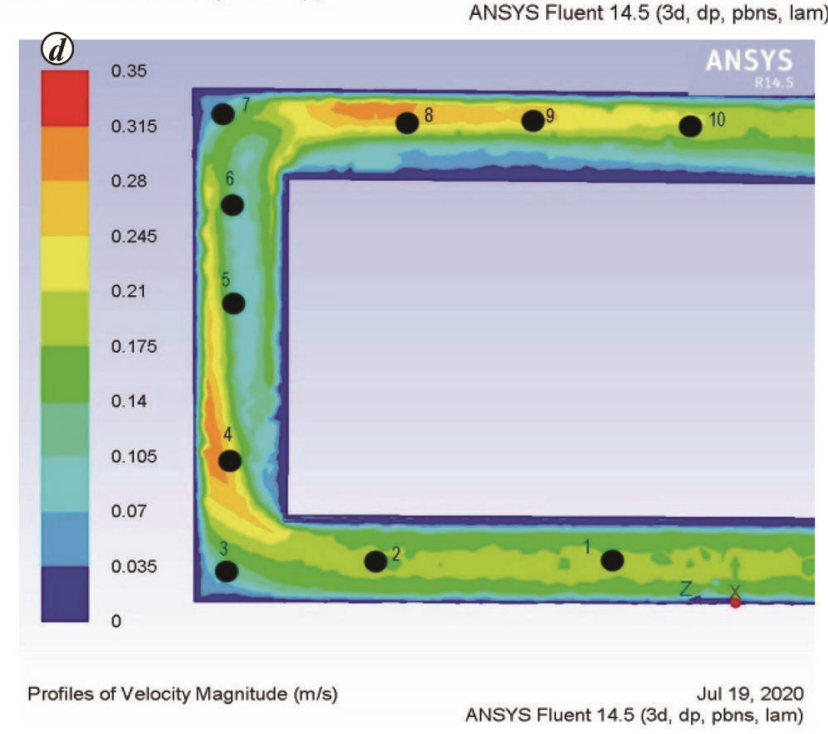

Figure 5. Variation of (a) density, (b) pressure, $(\boldsymbol{c})$ temperature and $(\boldsymbol{d})$ velocity inside district 2. 
considered as $1.16 \mathrm{~kg} / \mathrm{m}^{3}$ and the dynamic viscosity taken as $1.80 \times 10^{-5}$.

\section{Validation}

For validation velocity, temperature, pressure and density at the four corners of the three districts were measured using an anemometer, hygrometer, barometer and density was calculated manually using anemometer readings and dimensions of the galleries respectively (Figure 4). The measured values were compared with the simulated values (Table 7). The values for temperature, pressure and density obtained from CFD model were almost the same as the measured values. In case of velocity of air, variation between simulated and measured values is seen for velocities at the bottom corner points. The velocities at bottom corners 2 and 3 were less compared to those of the top corners 1 and 4 due to flow restriction because of the presence of a pillar in the main area. The difference between the simulated and measured velocities at 2 and 3 was because of the irregular structure of the pillars which are taken as uniform in shape in the case of simulated model. The velocities at 1 and 4 are less than the simulated values because of losses and also because of the assumption made that air is an incompressible fluid.

\section{Results and discussion}

\section{Variation in density, pressure, temperature and velocity}

Ten positions, four corner positions and six random positions have been selected in the entire working face of district 1 , to study the variation in density, pressure, temperature and velocity throughout the district (Figure 4). The same positions have been selected for districts 2 and 3 (Figures 5 and 6). It is seen that density remains almost the same for the entire area in all the three districts (Figures $4 a, 5 a$ and $6 a$ ). The pressure distribution is maximum at the corners 3 and 7 and decreases towards position 10 which is near the opening. This is due to the fact that velocity of air flow is minimum at the corners. The pressure distribution for districts 2 and 3 is nearly the same as district 1; the negative sign shows that there is a decrease in pressure (Figures $4 b, 5 b$ and $6 b$ ). The temperature is uniform throughout the area in district 1 . However, in districts 2 and 3, the difference between maximum and minimum temperatures is $3^{\circ} \mathrm{C}$ and $2^{\circ} \mathrm{C}$ respectively. The position of district 1 at the inlet of galleries where air circulation is more may be the reason for uniform distribution of temperature. The positions of districts 2 and 3 at the interior and the outlet end of the galleries respectively, might be the reason for non-uniform distribution. In both cases, corner 3 has the maximum temperature. Results indicate that the velocity of air is maximum at positions 4 and 8 which are on the path of airflow. Similarly, the velocity of air is minimum at positions 3 and 7 which are the corner points. The velocities are least at these positions because of the high-pressure zones created in them.

\section{Calculation of heat parameters of the body}

The heat parameters like heat loss from the body due to convection, radiation and heat storage of the body of a miner for all the three districts have been calculated using simulated values of velocity, temperature, pressure and density. If the number of workers increases, there will be an increase in ambient temperature which affects the human metabolic rate. The increase in temperature is given by $^{21}$

$$
\Delta t=\frac{q_{\mathrm{h}} \cdot n}{\rho_{\mathrm{a}} \cdot C_{\mathrm{e}} \cdot Q},
$$

where $\Delta t$ is the increase in temperature of air $\left({ }^{\circ} \mathrm{C}\right), q_{\mathrm{h}}$ the heat released by a human body $(0.25 \mathrm{~kW}), n$ the number of workers present, $\rho_{\mathrm{a}}$ the volumetric mass of air $(\mathrm{kJ} / \mathrm{kg})$, $C_{\mathrm{e}}$ the specific heat of air $(\mathrm{kJ} / \mathrm{K})$ and $Q$ is the air mass flow rate $\left(\mathrm{m}^{3} / \mathrm{s}\right)$.

The rise in temperature because of the heat released by a single human being inside the mine is $0.018^{\circ} \mathrm{C} /$ person. The number of persons assigned per shift of $8 \mathrm{~h}$ in this mine is 100 . Hence the total rise in ambient temperature is $100 * 0.018=1.8^{\circ} \mathrm{C}$. While calculating the convection rate (eq. (5)), the difference between skin temperature and clothing temperature is considered. The increase in both the temperatures due to increase in ambient temperature is 0.138 and 0.1774 times respectively (eqs (7) and (10)). Hence the increase in convection rate is negligible. Similarly, since the radiation rate (eq. (11)) is the difference between clothing temperature and ambient temperature, slight increase in both these temperatures will not cause significant increase in radiation rate. The average increase in temperature is less than $1.8^{\circ} \mathrm{C}$ as all the miners are not working in one position, but are distributed according to their jobs inside the mine.

Graphs were plotted between different positions in the mine and convection, radiation and heat storage for one worker for all the three districts (Figures 7-15).

The maximum heat loss due to convection from the body of a worker takes place at positions 4 and 8 because of proper air movement compared to the other positions, low air velocity and high pressure and temperature. The same trend is followed in the other two districts (Figures 10 and 13). The radiation from the body of the worker depends on the difference between the exterior temperature of the clothing and the ambient temperature. If the difference between these temperatures is large, the radiation also will be more. The maximum radiation takes 
RESEARCH ARTICLES
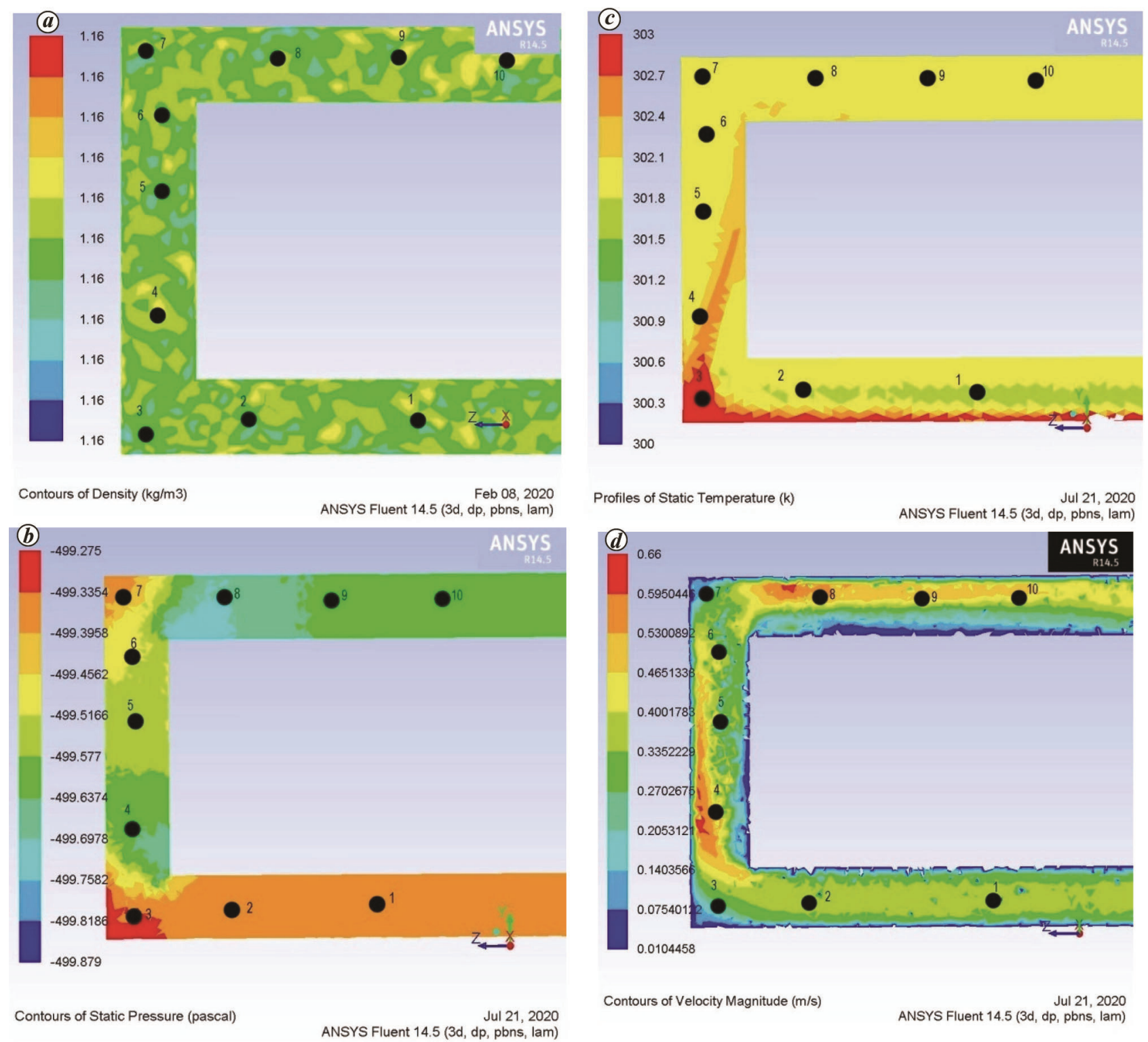

Figure 6. Variation of (a) density, $(\boldsymbol{b})$ pressure, $(\boldsymbol{c})$ temperature and $(\boldsymbol{d})$ velocity inside district 3.

Table 8. Heat storage and comfort relationship

\begin{tabular}{lll}
\hline Heat storage value & Thermal sensation & Comfort sensation \\
\hline$S>>0$ & Very hot & Very uncomfortable \\
$S>0$ & Hot & Uncomfortable \\
$S=0$ & Neutral & Comfortable \\
$S<0$ & Cold & Slightly uncomfortable \\
$S<<0$ & Very cold & Uncomfortable \\
\hline
\end{tabular}

place at positions 3 and 7 , whereas the least radiation takes place at positions 4 and 8 in districts 1 and 3 (Figures 8 and 14). The reason for this may be that 3 and 7 are corner positions. Similarly, 4 and 8 are on the path of air and hence temperature difference is less. However, in district 2 the radiation at position 3 is less (Figure 11).
Since there is a sudden increase in temperature at position 3 , the difference between clothing temperature and ambient temperature reduces and hence radiation decreases. With the increase in radiation, the workers are uncomfortable. Table 8 shows the heat storage value and comfort relationship ${ }^{22-24}$.

The miners with moderate work rate are near the neutral line in all the districts (Table 7; Figures 8, 11 and 14). Those with the hard and very hard work rate have maximum heat storage, while the miners with light work rate and those at rest have minimum heat storage. The heat storage of the body is same in all the positions according to the severity of work in districts 1 and 3 . However, in district 2 there is a deviation at position 3, which gives a higher heat storage value than the other positions. It can be seen from the analysis that of all the 
points, position 3 of district 2 is the most uncomfortable place to work inside this particular mine.

\section{Conclusion}

The ventilation system plays an important role in the comfort of miners. The health of the miners is an impor-

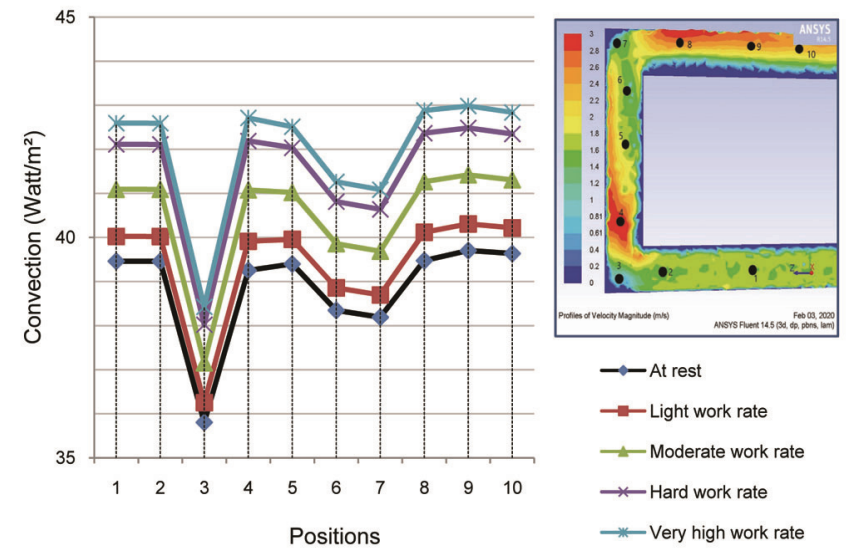

Figure 7. Convection heat loss from the body of workers $\left(\mathrm{W} / \mathrm{m}^{2}\right)$ at various positions (district 1 ).
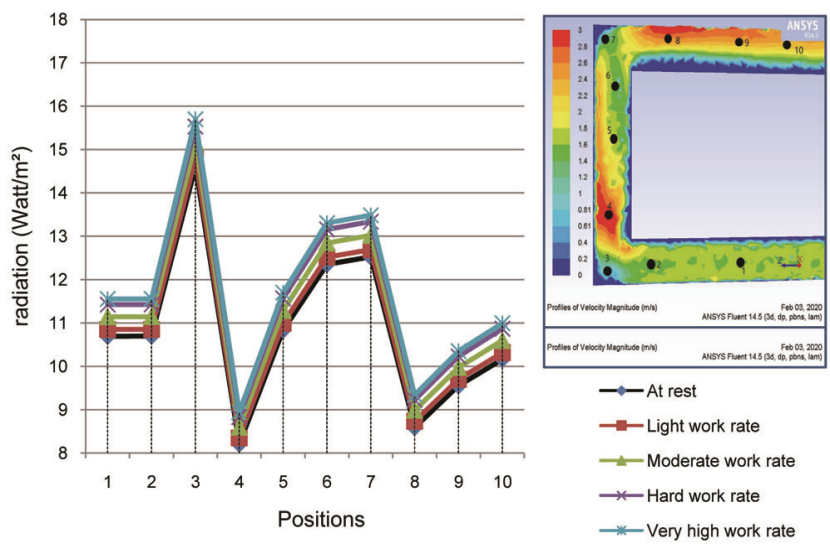

Figure 8. Radiation from the body workers $\left(\mathrm{W} / \mathrm{m}^{2}\right)$ at various positions (district 1).

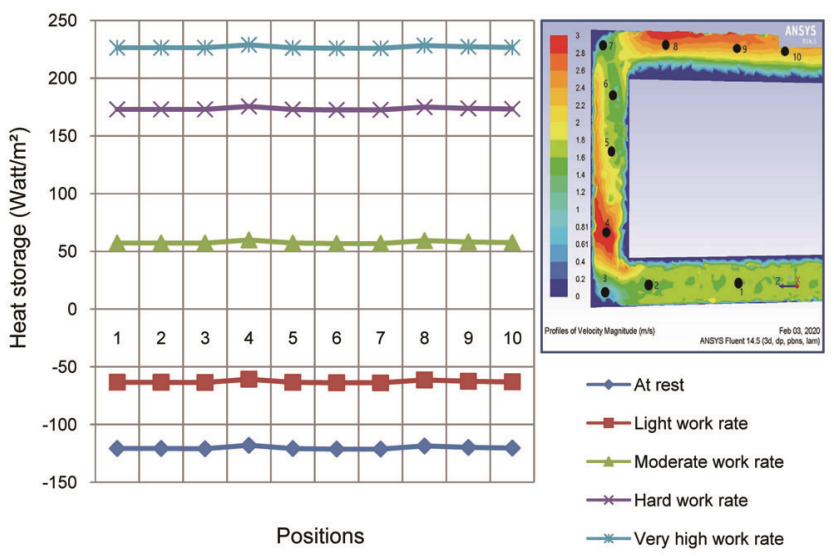

Figure 9. Heat storage $\left(\mathrm{W} / \mathrm{m}^{2}\right)$ at various positions (district 1). tant factor along with focusing on the target of coal production. This article is an analysis of heat exchange between the miners and their environment, which is quantified using the ANSYS model. It includes two major objectives. The first is simulation of the parameters of ventilation using CFD and the second is calculation of heat stress based on the simulated parameters for the

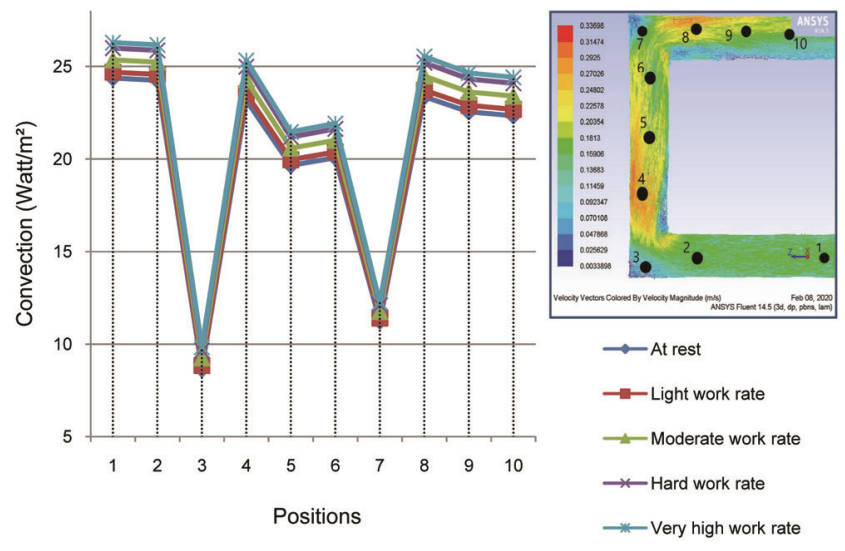

Figure 10. Convection heat loss from the body of workers $\left(\mathrm{W} / \mathrm{m}^{2}\right)$ at various positions (district 2).

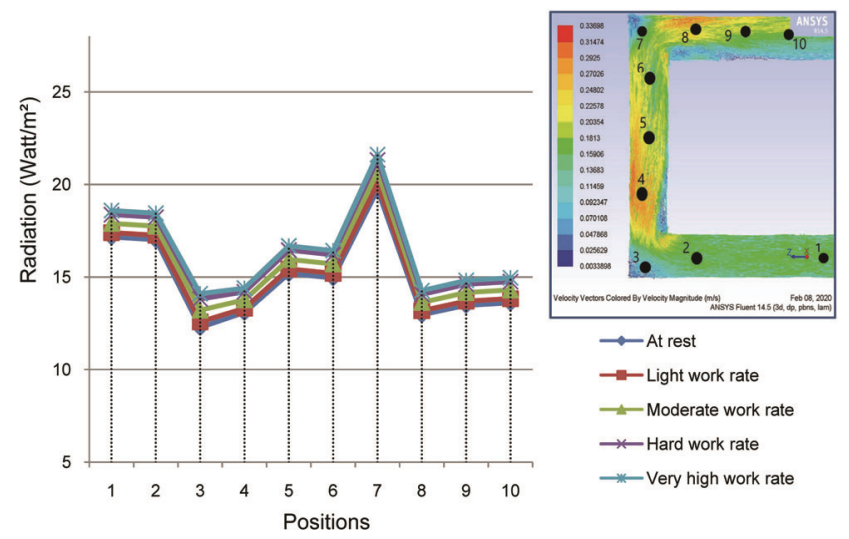

Figure 11. Radiation $\left(\mathrm{W} / \mathrm{m}^{2}\right)$ at various positions (district 2).

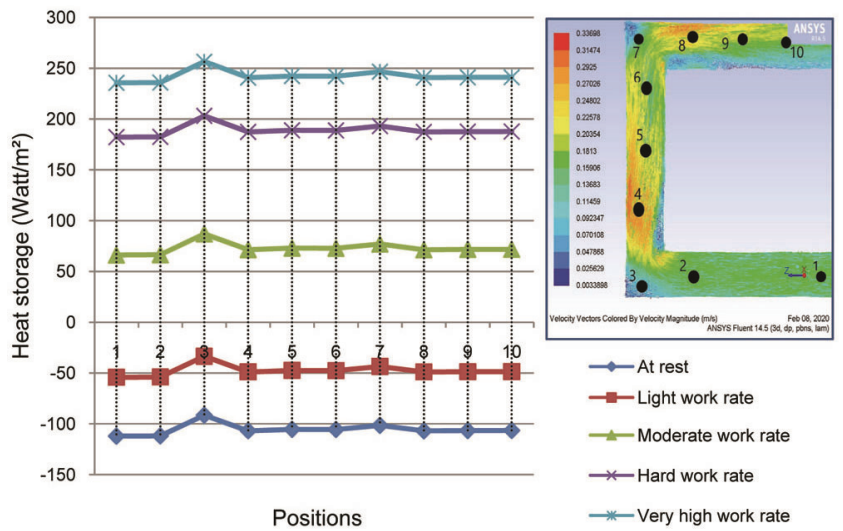

Figure 12. Heat storage $\left(\mathrm{W} / \mathrm{m}^{2}\right)$ at various positions (district 2). CURRENT SCIENCE, VOL. 121, NO. 2, 25 JULY 2021 


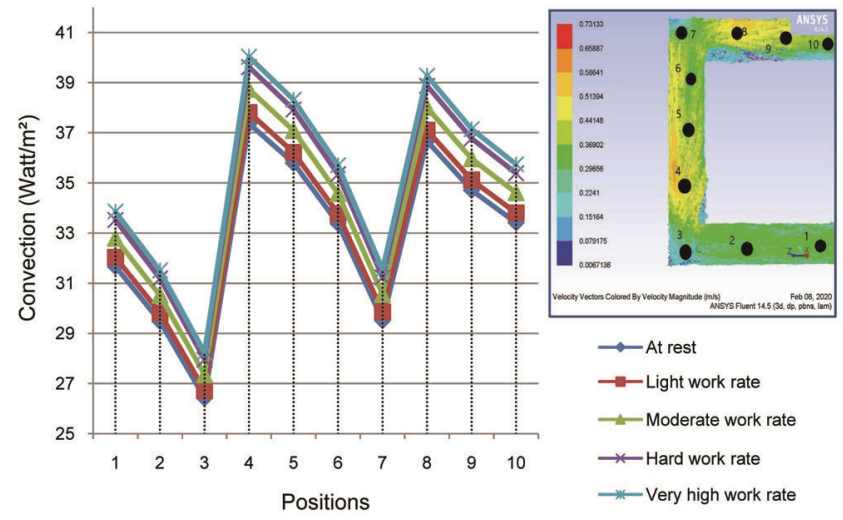

Figure 13. Convection heat loss from the body of workers $\left(\mathrm{W} / \mathrm{m}^{2}\right)$ at various positions (district 3 ).

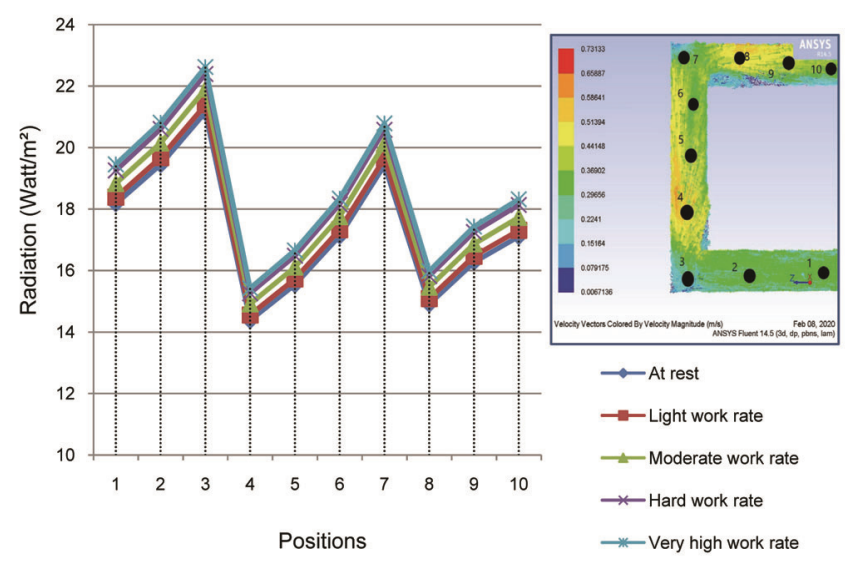

Figure 14. Radiation $\left(\mathrm{W} / \mathrm{m}^{2}\right)$ at various positions (district 3 ).

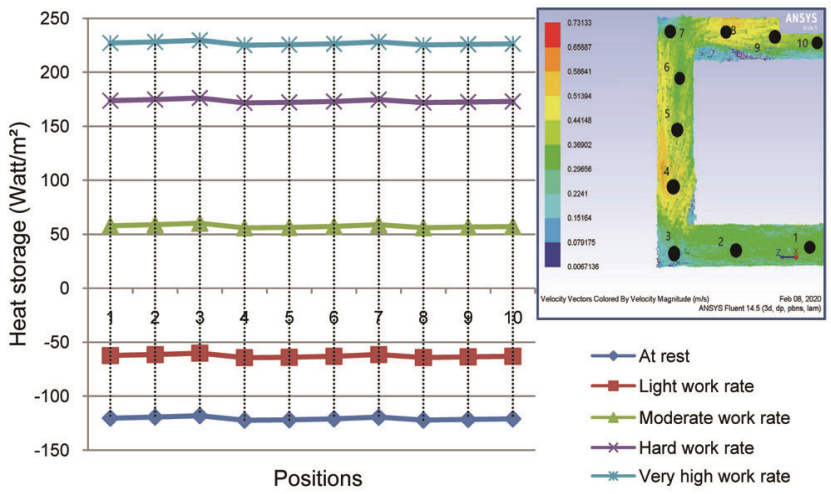

Figure 15. Heat storage $\left(\mathrm{W} / \mathrm{m}^{2}\right)$ at various positions (district 3$)$.

comfort of the miners. The results can be summarized into the following points:

- The simulated results and measured values are comparable. The parameters of a complete mine can be simulated. Hence there is no need to measure the parameters using instruments at every place inside the mines, especially at the critical blind galleries which are hard to reach.

- The blind galleries can be easily identified and the flow parameters can be analysed, which helps in understanding the ventilation conditions and requirements for adequate ventilation inside the coal mines.

- The study also helps determine the environmental conditions and to identify the perfect position for the workers according to the type of mine, its depth, the number of workers, velocity, temperature, pressure and density.

- The study highlights how the metabolic rate and other heat stresses depend on the environmental conditions. This can be used to monitor the factors that affect the health of the miners.

- The structure and various geometrics of the mine can be easily analysed and how the movement of air depends on the canopy of the seam can be understood by simulation.

- The zones where mine fire can occur and the requirements of ventilation equipment at the blind galleries can be hypothetically analysed.

Conflict of interest: The authors declare no conflict of interest.

1. Power sectors of all India, administration of National Electricity Policy, Ministry of Power and Government of India, February 2020.

2. Kishore, B., Future of Bulk Production from Underground Coal Mine in India. Coal Mining Technology and Management (CMTM), June 2018, vol. 21(1).

3. Ren, T. and Balusu, T., The use of CFD modelling as a tool for solving mining health and safety problems. In 10th Underground Coal Operators' Conference, University of Wollongong and the Australasian Institute of Mining and Metallurgy, 2010, pp. 339349.

4. Ren, T. and Wang, Z., Computational fluid dynamics modelling of respirable dust and gas behaviour on a longwall face. In Australian Mine Ventilation Conference, Australian Institute of Mining and Metallurgy, Australia, 3 July 2013, pp. 191-200.

5. Lu, Y., Saad, A., Sasmito Agus, P. and Kurnia Jundika, C., Prediction of air flow, methane, and coal dust dispersion in a room and pillar mining face. Int. J. Min. Sci. Technol., 2017, 27(4), 657662.

6. Liu, H., Mao, S., Li, M. and Yue, J., 3D simulation for dynamic characteristics of airflow and dust control in a laneway of coal mine. In 24th International Conference on Geoinformatics, Galway, 2016, pp. 1-6; doi:10.1109/GEOINFORMATICS.2016. 7578972 .

7. He, D. C. and Xueqiu, X. N., Numerical simulation of airflow distribution in mine blind galleries. Int. J. Min. Sci. Technol., 2017, 27(4), 663-667.

8. Vancho, A., Dejan, M., Zoran, D. and Stojance, M., CFD simulation of the brattice barrier method for approaching underground mine fires. Min. Sci., 2016, 23, 161-172; doi:10.5277/msc162313.

9. Javier, T., Susana, T., Mario, M., Malcolm, G. and Judith, V., Models of methane behaviour in auxiliary ventilation of underground coal mining. Int. J. Coal Geol., 2009, 80(1), 35-43.

10. Fluent Inc., FLUENT user's guide, 2006. 
11. ISO 7243. Hot environments estimation of the heat stress on working man, based on the WBGT-index (wet bulb globe temperature), 1989.

12. Hettinger, T. H., Peters, H., Noack, M. and Muller, B. H., Validation of the thermal indices for the evaluation of the heat load in steel industry. Final report of ESCS research contract, 1986.

13. Mairiaux, P. and Malchaire, J., Comparison and validation of heat stress indices in experimental studies. Ergonomics, 1995, 38, 5872.

14. Mcpherson, M. J., Subsurface Ventilation and Environmental Engineering, Chapman and Hall, London, 1992.

15. Lotens, W. A. and Havenith, G., Effects of moisture absorption in clothing on the human heat balance. Ergonomics, 1995, 38, 10921113.

16. ISO 9920. Ergonomics of the thermal environment - estimation of thermal insulation and water vapour resistance of a clothing ensemble, 2007.

17. Lee, J.-H., Kim, Y.-K., Kim, K.-S. and Ki, S., Estimating clothing thermal insulation using an infrared camera. MDPI J., 2016, 16(3), 341; https://doi.org/10.3390/s16030341.

18. Mcpherson, M. J., Subsurface Ventilation Engineering, Mine Ventilation Service, Inc., Fresno, 2009.

19. ISO 7933, Ergonomics of the thermal environment - analytical determination and interpretation of heat stress using calculation of the predicted heat strain, 2004.
20. Waclawik, J. and Branny, M., Numerical modelling of heat exchange between a human body and the environment. Arch. Min. Sci., 2004, 49, 223-251.

21. Hartman, H. L., Mutmansky, J. M., Ramani, R. V. and Wang, Y. J., Mine Ventilation and Air Conditioning, John Wiley, New York, 1997.

22. Epstein, Y. and Moran, D. S., Thermal comfort and the heat stress indices. Ind. Health, 2006, 44, 388-398.

23. King, J., Thermoregulation: physiological responses and adaptations to exercise in hot and cold environments. J. Hyperplasia Res., 2004, 4.

24. Shapiro, Y. and Epstein, Y., Environmental physiology and indoor climate thermoregulation and thermal comfort. Energy Build, 1984, 7, 29-34.

ACKNOWLEDGEMENT. We thank Sunil Kumar (Safety Officer, Shankarpur Colliery), Uday Prasad (Survey Officer, Shankarpur Colliery), and the staff and management for their active involvement in the underground survey.

Received 15 September 2020; revised accepted 11 May 2021

doi: $10.18520 / \mathrm{cs} / \mathrm{v} 121 / \mathrm{i} 2 / 264-274$ 